\title{
OCCASIONAL PIECE
}

\section{Beating jet lag}

\section{J Milne, M H Fuard}

Br J Sports Med 2007;41:401. doi: 10.1136/bjsm.2006.034066

Jet lag is often cited as a cause of poor sporting performance. We report on the case of a rugby league player who flew $20000 \mathrm{~km}$ and 12 time zones, then repeated the feat a few days later, prior to playing with distinction in an important final match in an international series.

See end of article for authors' affiliations

Correspondence to: Dr C J Milne, Anglesea Clinic, PO Box 4362 Hamilton 3204, New Zealand; chris@angleseaphysioand sports.co.nz

Accepted 6 January 2007 Published Online First 26 January 2007 etlag can cause impaired sporting performance, who flew halfway around the world and back, and helped his team win a memorable rugby league competition.

On 26 November 2005, New Zealand beat Australia 24-0 in the grand final of the Gillette Tri-Nations series. The New Zealand halfback and key playmaker and goal kicker in that game was Stacey Jones. His nickname was the "Little General". Jones had been transferred from the New Zealand Warriors and was due to start playing for his new club, Les Catalans, in France. He played in the first two tests before flying to France. From there, he was convinced to come out of retirement for several further matches in Great Britain and France. He flew back to New Zealand, a distance of approximately $20000 \mathrm{~km}$ (and 12 time zones) to be present at the birth of his son by elective caesarean section on 24 November 2005. Although back in New Zealand, he heard that his Kiwi team had qualified for the Tri-Nations final. A few hours after the birth, he boarded a plane to fly back to Great Britain, a further $20000 \mathrm{~km}$ and 12 time zones. He arrived in Manchester just 1 day before the final match. He had flown to New Zealand and back (some $40000 \mathrm{~km}$ ) in a span of 6 days. His performance in the final was up to its usual high standard, directing play effectively, plus he kicked a conversion and three penalty goals.

Quoted in a publication ${ }^{1}$ released soon after the event he said, "The hardest part for me was the warm-up for the final. Once you're out on the field the adrenalin kicked in. I got to halftime and felt a bit tired for the first part of the second half, but soon enough I was away again".

How did he do it? He took Triazolam $(0.25 \mathrm{mg}$, two tablets before sleep) at an appropriate time during the flights to and from New Zealand, plus melatonin (two tablets before sleep). Travel medical publications ${ }^{2-4}$ offer advice on the use of medication to minimise the effects of time zone but not always. We report the case of a player

\section{What is already known}

- Jet lag affects people travelling across several time zones, with effects proportional to the number of time zones crossed.

- Effects vary between individuals, but can be lessened by adhering to travel guidelines.

\section{What this study adds}

- This case report demonstrates that it is possible for elite athletes to perform with distinction after round the globe travel, provided they adhere to travel guidelines.

change. Yung et $a l^{4}$ recommend melatonin, 3-5 mg, to be taken at bed time (local time) starting the first evening after arrival and continuing for the next 5 days. By contrast, the World Health Organization publication ${ }^{3}$ is pretty sceptical regarding melatonin, but does recommend shortacting sedatives.

To our knowledge, this is the most extraordinary sporting performance after extended international travel over many time zones. The take home message is that, with appropriate advice and selective use of medications, travel across many time zones need not be associated with a detriment in performance in the sporting arena.

\section{Authors' affiliations}

C J Milne, Anglesea Clinic, Hamilton, New Zealand M H Fuard, Frankton Lake Road Medical Centre, Hamilton, New Zealand

Informed consent was obtained for publication of the person's details in this report.

\section{REFERENCES}

1 Leitch PC, Becht R. The year the Kiwis flew. Auckland: Harper Collins, 2006.

2 Ellis-Pegler R, Ingram J. Health advice for overseas travellers. Wellington: Ministry of Health, 1996.

3 World Health Organization. International travel and health. Vaccination requirements and health advice. Geneva: World Health Organization, 2005.

4 Yung A, Ruff T, Torres J, et al. Manual of travel medicine. 2nd edn. Melbourne: IP Communications, 2004:229-32. 